\title{
Review on Automatic Sanitizer Dispensing Machine
}

\author{
Akshay Sharma A S \\ Student, \\ Department of Electronics and Communication Engineering, \\ Vidyavardhaka College of Engineering Mysore, India
}

\begin{abstract}
An automatic hand sanitizer dispensing machine is automated, non contact, alcohol based hand sanitizer dispenser, which finds it's use in hospitals, work places, offices, schools and much more. Alcohol is basically a solvent, and also a very good disinfectant when compared to liquid soap or solid soap, also it does not need water to wash off since it is volatile and vaporizes instantly after application to hands. It is also proven that a concentration of $>70 \%$ alcohol can kill Coronavirus in hands. Here, an ultrasonic sensor senses the hand placed near it, the Arduino uno is used as a microcontroller, which senses the distance and the result is the pump running to pump out the hand sanitizer.
\end{abstract}

Keywords:- Sanitizer, Pump, Alcohol, Soap, Coronavirus, Ultrasonic Sensor, Relay

\section{INTRODUCTION}

Sanitization means cleaning or sterilizing an object or body part like hands or whole body. Sanitization can be done in many ways including UV Sanitization, Soap Sanitization, Alcohol Sanitization, Bleach Sanitization and so on. Of the above methods, alcohol was found to be more useful for human beings since it is harmless on skin surface, vaporizes easily and kills most of the viruses, bacteria, and also removes dirt in our hands. Alcohol may be expensive for mass scale sanitization of buildings or rooms and a major disadvantage is that, alcohol is highly inflammable and requires careful storage to avoid catastrophe. Alcohol also makes hands dry since it absorbs moisture, and hence also needs addition of moisturizers. Alcohol based hand sanitizers are also provided with antiseptic disinfectants like Chlorohexidine Gluconate. Minimum concentration of alcohol in hand sanitizers must be greater than $70 \%$ for effectiveness against viruses. But, repeatedly touching the hand sanitizer containers to get a drop of sanitizer again initiates contact with persons, which may be risky. Hence there is need for non contact based hand sanitizer dispenser.

\section{LITERATURE SURVEY}

In [1], the paper mainly says about the hospital grasped infections, which is about 2 Million Patients per year and also says that it is $8^{\text {th }}$ leading cause for deaths annually in USA. It also says that handwashing is important and also effective with proper hand washing steps, but washing with soap and water is time consuming for peak hours in hospitals. This paper also showed the effectiveness of the alcohol based hand sanitizers, which reduced infection rates by whopping $30 \%$. They used hand sanitizers with 60 to 70 percent ethanol or isopropanol for reducing significant number of pathogens. The patients were also given about 4.25 ounce containers of hand sanitizer alongside their beds.
For 10 month period of using hand sanitizers showed a result of $36.1 \%$ infection reduction.

In [2], the paper says about the infection caused by drug resistant micro-organisms which causes increase in death rate and also complications, the multidrug resistant bacteria includes Methicillin Resistant Staphylococcus aureus(MRSA), Extended Spectrum Beta-lactamase (ESBL) producing bacteria, Multidrug Resistant Pseudomonas aeruginosa(MDRP), which are very common worldwide. Several antibiotics have increasing multidrug bacteria isolation rate, even personal protection equipment(PPE) can't be effective in isolation rate of MSRA. Hence they emphasize about the use of alcohol based hand sanitizers since the alcohol based hand sanitizers had negative association with MRSA isolation rate, which means that hand hygiene is very important in hospitals.

In [3], the paper says about emergence of the novel Coronavirus( SARS-CoV-2), which has caused unexpected challenges to health of the people of this world, the paper also aims at reducing the transmission rate of the disease. The paper explains about the virus structure and how is it different from that of the bacterial structure, which means that virus has single stranded or double stranded RNA or DNA encapsulated in 'capsid' and virus can replicate only in presence of a host and described as 'living entities'. Bacteria also has almost the same structure including DNA or RNA along with 'Cell Membrane' and can replicate without a host. The paper also gives a complete comparison between hand sanitizers and soap, foam vs gel, and it says that high concentration of ethanol can reduce the amount of virus particle present in the hand and hence proves the effectiveness of alcohol based hand sanitizer.

\section{METHODOLOGY}

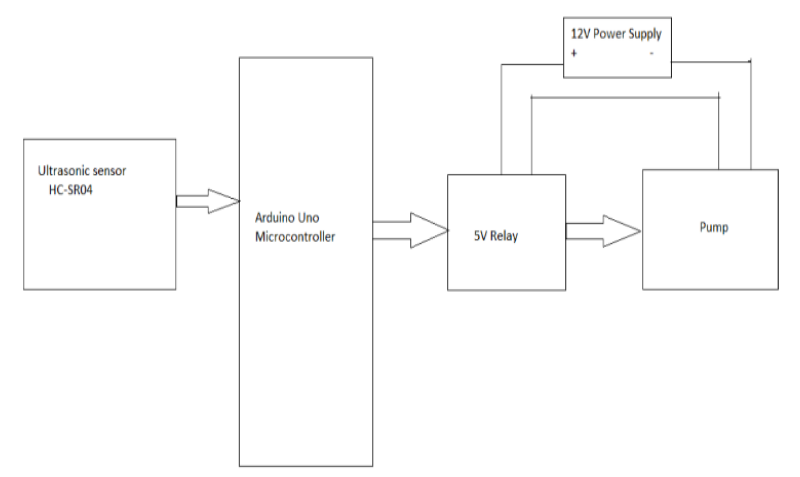


Here, An Arduino Uno microcontroller is used since it is easy to program, has inbuilt ADC, DAC. The input to the Arduino is given using an ultrasonic sensor, which is used to sense the distance, it emits ultrasonic frequency from one side and the notes the time taken by sound wave to get reflected back. When the sensor senses the hand, at a distance less than $7 \mathrm{~cm}$ from the sensor, the Arduino gives a $100 \mathrm{~ms}$ pulse from it's digital output pin. The pump cannot be used directly, hence a relay is used as a switch. The relay accepts the pulse from Arduino and makes the pump run. The pump is 3 to $12 \mathrm{~V}$ submersible type, which pumps out a few drops of hand sanitizer on to the hands, after pumping, the distance is sensed for every $1000 \mathrm{~ms}(1 \mathrm{~s})$ for scanning purposes.

\section{RESULTS AND DISCUSSIONS}

In the above paper, Arduino is used as a microcontroller for calculating the distance between the sensor and the hand placed below it. If it is less than $7 \mathrm{~cm}$, then pump runs for $100 \mathrm{~ms}$ through a relay and pumps out few $\mathrm{mL}$ of liquid alcohol based hand sanitizer and also senses the distance for every $1000 \mathrm{~ms}$. Components like pump, relay, Arduino microcontroller were tested. The Hand Sanitizer used was liquid type with Isopropanol and Chlorohexidine Gluconate $(0.3 \%)$. This can also be used for gel type hand sanitizer also.

\section{CONCLUSION}

From the above paper, we come to know that alcohol based hand sanitizers are more effective than soaps, and also easy to use. The paper also says that non contact dispensing is again important to prevent pathogen spreading and finally, hand hygiene is most important and must be part of our daily life

\section{REFERENCES}

[1] Jessica Hillburn MT(ASCP),CIC, Brian S Hammond, Elanor J Fendler PhD, Patricia A Groziak MS, "Use of alcohol hand sanitizer as an infection control strategy in acute care facility", American Journal of infection control Volume 31,Issue 2, April 2003.

[2] Satoru Mitsuboshi, Masami Tsugita, "Impact of alcohol-based hand sanitizers,antibiotic consumption, and other measures on detection rates of antibiotic resistant bacteria in rural Japanes hospitals", Journal of Infection and Chemotherapy, 2018.

[3] Golin, A. P., Choi, D., \& Ghahary, A. "Hand Sanitizers: A Review of Ingredients, Mechanisms of Action, Modes of Delivery, and Efficacy Against Coronaviruses". American Journal of Infection Control ,2020.
AUTHOR

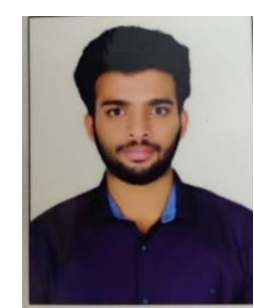

Akshay Sharma A S, is a student of Vidyavardhaka College of Engineering, Mysuru, Karnataka. He was born on $6^{\text {th }}$ of June, currently pursuing bachelor of engineering (B.E) Degree in Electronics and communication from Vishveshvaraya Technological University, Belagavi ,Karnataka, India. Power Electronics and Networking is his area of interest. 